\title{
Es ist die Kultur, Dummchen!
}

\section{Liebe Leserinnen und Leser,}

Kultur ist bei den meisten Controllern kein sehr beliebter Begriff. Zu schwammig, zu schwer zu fassen und noch weniger leicht zu verändern. Dagegen steht die Erfahrung, dass die Einführung von Prozessen und Systemen gegen eine etablierte Unternehmenskultur regelmäßig zum Scheitern verurteilt ist. Wir an der WHU sind daher fest davon überzeugt, dass Controller für eine Performance- beziehungsweise Controlling-Kultur im Unternehmen kämpfen sollten, ja kämpfen müssen. Damit meinen wir nicht etwa eine falsch verstandene Kontrollkultur oder eine Kultur des Vermeidens von Fehlern und Überraschungen. Nein, eine Controlling-Kultur besteht in unseren Augen aus drei zentralen Bausteinen: einer Kultur der konsequenten Zielorientierung und der Übernahme von Verantwortung auf dem Weg dahin, einer Kultur der Transparenz und des offenen Informationsaustauschs - auch über Abteilungs- und Bereichsgrenzen hinweg - und schließlich einer Kultur der Analyse und der konstruktiven Kritik, in der die Kraft des besseren Arguments dominiert.

Häufig sehen wir in praxi gerade bei der zweiten und der dritten Komponente einer idealtypischen Controlling-Kultur noch Defizite. Dabei sind auch diese Bausteine so wichtig. Eine im letzten Jahrgang dieser Zeitschrift veröffentlichte WHU-Studie hat klar gezeigt, dass ein offener Informationsaustausch und eine Kultur der konstruktiven Kritik die zentralen Treiber eines erfolgreichen Umgangs mit Volatilität sind (und nicht etwa die Anpassung oder Einführung entsprechender Instrumente). Auch im Kontext der Einführung neuer Entscheidungsunterstützungssysteme haben wir die Erfahrung gemacht, dass etwa der erfolgreiche Einsatz eines Digital Boardrooms von SAP oder ähnlicher Produkte nicht zuletzt von den genannten kulturellen Komponenten abhängt: Ohne die Bereitschaft zur offenen und weitgehend politikfreien Diskussion, ohne das Commitment zur Kraft des besseren Arguments verkommt jeder digital unterstützte Besprechungsraum zur ebenfalls digitalen Makulatur.

Controller werden sich in Zukunft nicht mehr in der Komfort- und Kuschelzone formaler Prozesse und Systeme verstecken können. Warum? Weil diese ganz oder weitgehend im Shared Service verschwinden oder automatisiert werden.

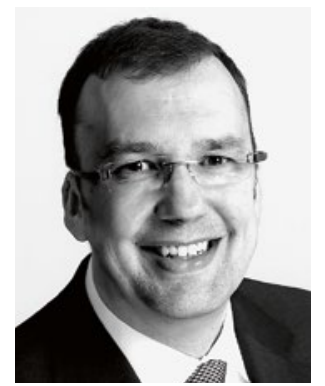

Utz Schäffer

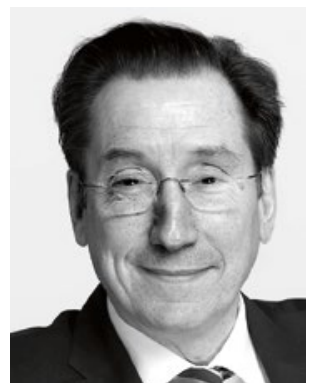

Jürgen Weber
Gleichzeitig werden Manager durch Self-Service Business Intelligence in die Lage versetzt, selbstständig(er) Analysen durchzuführen und Entscheidungen anzustoßen. Der Informationszugang wird demokratisiert. Damit gewinnt aber die Rationalitätssicherung in den darauf aufbauenden informellen Prozessen immer mehr an Bedeutung. Genau hier liegt zunehmend der entscheidende Engpass für eine wirklich rationale Unternehmensführung - nicht in dem einen oder anderen instrumentellen oder prozessualen Detail. Und auch wenn es eines zusätzlichen Arguments eigentlich gar nicht mehr bedarf: Große Teile der jungen, nachwachsenden Generation von Leistungsträgern werden auf Dauer nicht mehr ohne eine überzeugende Kultur der klaren Zielorientierung, des offenen Informationsaustauschs und der Kraft des besseren Arguments zu motivieren sein. Kurzum: Wir sind überzeugt, dass in der Gestaltung der Performance- beziehungsweise der ControllingKultur des Unternehmens der zentrale Erfolgsfaktor liegt! Das $\mathrm{zu}$ ignorieren ist in unseren Augen keine Alternative.

Viel Vergnügen bei der Lektüre wünschen Ihnen
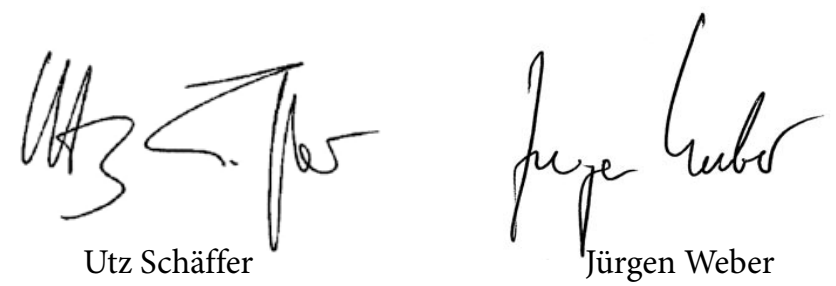